\title{
The Pattern of Use of Medical Masks Among Health Care Professionals During Covid 19 Pandemic in South East Nigeria University Teaching Hospitals
}

\author{
Uche Sebastine Ozioko ${ }^{1, ~}$, Emmanuel Chino Iyidobi ${ }^{1}$, Onyinye Mary Ozioko ${ }^{2}$, \\ Ignatius Ikemefuna Ozor ${ }^{3}$, Chisom Ogbonnaya Mbaeze ${ }^{1}$, Ifeanacho Ezeteonu Abireh ${ }^{3}$ \\ ${ }^{1}$ Department of Orthopaedic Surgery \& Trauma, National Orthopaedic Hospital, Enugu, Nigeria \\ ${ }^{2}$ Department of Anatomy, College of Medicine, Enugu State University of Science and Technology, Enugu, Nigeria \\ ${ }^{3}$ Department of Surgery, College of Medicine, Enugu State University Teaching Hospital Parklane, Enugu, Nigeria
}

Email address:

ozonalman@yahoo.com (U. S. Ozioko)

${ }^{*}$ Corresponding author

\section{To cite this article:}

Uche Sebastine Ozioko, Emmanuel Chino Iyidobi, Onyinye Mary Ozioko, Ignatius Ikemefuna Ozor, Chisom Ogbonnaya Mbaeze, Ifeanacho Ezeteonu Abireh. The Pattern of Use of Medical Masks Among Health Care Professionals During Covid 19 Pandemic in South East Nigeria University Teaching Hospitals. International Journal of Infectious Diseases and Therapy. Vol. 8, No. 3, 2020, pp. 81-87. doi: $10.11648 /$ j.ijidt.20200503.18

Received: July 24, 2020; Accepted: August 10, 2020; Published: August 20, 2020

\begin{abstract}
In history, pandemic outbreaks have wiped out populations as well as paved way for innovations and advances in Medicine and Public health. This study aims to ascertain the inherent knowledge gap and practice regarding the use of medical mask by healthcare workers during Covid-19 pandemic. Methods. This cross sectional survey was conducted at six tertiary hospitals within the south east Nigeria in April-June 2020 using convenient sampling method, a total of 273 respondents was enrolled in the study. A three components questionnaire comprising demographic inquiries, questions was designed to assess knowledge and practice of healthcare professionals regarding the use of medical mask. Collated data was analysed using SPSS software version 21. Result, $73.3 \%$ of the participant thought they knew the procedural steps in the use of medical mask however only $18.3 \%$ healthcare workers had good practice on the use of medical mask. Significant difference. $(p<0.05)$ in total mean knowledge among different cadres of healthcare workers was observed and total percentage of participant with good knowledge and practice of the use of medical mask were $37 \%$ and $17.1 \%$ respectively. A weak positive correlation was also observed between knowledge and practice regarding the use of medical mask among health care professionals in south east Nigeria university teaching hospital. Conclusion: Findings from this study has reaffirmed the importance of continuous medical education thus knowledge and practice of the use of medical mask should be emphasized according to international standards to ensure they offer optimal product performance when used by healthcare professionals.
\end{abstract}

Keywords: Corona Virus, Healthcare Professionals, Medical Masks

\section{Introduction}

Epidemics of re-emerging infectious diseases are on the rise, with catastrophic health, social and economic implications especially in the developing countries.

Infectious disease surveillance has long presented a major public health challenge in Nigeria, given its size and complexity [1].
MacIntyre, [2] has reported the effectiveness of medical mask in reducing the risk of infection among healthcare workers and in the community.

Coronavirus disease 2019 (COVID-19) is a potentially severe acute respiratory infection caused by severe acute respiratory corona virus 2 (SARS-CoV-2). In December 2019, 
a number of patients with pneumonia of unknown aetiology emerged in Wuhan City, Hubei Province, Central China. Genome sequencing has demonstrated that this pneumonia, was caused by this novel virus previously known as 2019 novel coronavirus (2019-nCoV) [3-5]. The clinical presentation is that of respiratory infection with a symptom ranging from a mild flu like illness, to a severe viral pneumonia leading to acute respiratory distress syndrome and multiple organ dysfunction that could lead to death in about $2-3 \%$ of infected case.

The World Health Organization declared the outbreak of this virus a public health emergency of international concern on $30^{\text {th }}$ January 2020 and subsequently declared it a pandemic on $11^{\text {th }}$ March 2020 [6]. Since its emergence, the virus has spread rapidly across the globe, leading to over a millions confirmed cases in three months. As of 13 June 2020, more than 7.66 million cases of COVID-19, 426,000 deaths and more than 3.64 million patients have reportedly recovered in more than 188 countries and territories, [7]. In Nigeria, the first case of COVID-19 was detected on 27 February 2020. The epidemic trajectory has been slow, in part, due to the public health interventions implemented in Nigeria, which reduced both community transmission and importation [8, 9]. Though still battling to flatten the infectivity rate curve, as at $13^{\text {th }}$ June total confirmed cases recorded 15,181, Active cases 9,891 discharged home 4,891 and 399 death from the dreaded virus. [10]

Healthcare workers exposed to dangers like pathogen exposure, long working hours, psychological distress, fatigue, and physical violence are the frontline of COVID19 pandemic response hence a more vulnerable population [11]. The latest global statistics shows thousands of health care workers getting infected with some percentage of them dying from the covid -19 virus [12]. In Nigeria as of $5^{\text {th }}$ June 2020 the number of healthcare workers that got infected with Covid 19 rose up to 812. [13]. The challenges were practically due to lack of personal protective equipment, ill equipped hospitals, poor knowledge on infection prevention control measures which include proper use of personal protective equipment, hand washing, cough etiquette and social distancing, lack of testing kits and equipped molecular laboratories for prompt diagnosis of suspected cases.

Human to human transmission of this novel virus occurs via close contacts with respiratory droplets produced when a person exhales, sneezes or coughs, formites and fecooral route. $[14,15]$. It was initially thought that coughing yield the highest droplets of the virus, however recent studies has shown that talking is the most important means of transmission with louder speech creating larger quantities of droplet with high viral load [16]. This transmission dynamics of this novel virus has been established based on past experience of SARS-CoV outbreak in 2003 [17-19].

To prevent infections in hospital settings, World Health Organisation recommends the use of contact and droplets precautions by health care workers caring for patients with covid 19. [20]. Medical masks are defined as procedural mask that are flat or pleated which are affixed to the head with bands that goes round the ears or head or both. Its performance is evaluated over a set of standardize test methods that aim to balance high filtration, adequate breathability, and optionally fluid penetration resistant. [21]. It is a vital component of personal protective equipment and appropriate use and disposal of these mask by healthcare workers is paramount in curbing the transmission of this virus. The use of medical mask among health care workers is strongly recommended by World Health Organization and the Center for Disease Control and prevention as a standard for transmission based precaution [22].

Till date there is paucity of literature on knowledge, attitude and practice of healthcare workers on the appropriate use of medical mask in forestalling community transmission of corona virus 2019. Thus this study aims to assess the knowledge and practice of the use of medical mask by healthcare professional as one of the preventive tool in curtailing the spread of corona virus 2019.

\section{Method}

\subsection{Investigation Design}

This cross sectional survey was conducted at six tertiary hospital within the south east Nigeria in April-June 2020. A convenient sampling method was used and a sample size of 253 was calculated considering 5\% Precision and 95\% confidence interval. A total of 273 respondents was enrolled in the study.

\subsection{Ethical Approval}

Ethical Approval was sought and gotten from Research Education and Training Committee. (RETC) of National Orthopaedic Hospital Enugu Nigeria. The study was conducted in accordance with World Medical Association Declaration of Helinski Ethical Principles for Medical Research Involving Human Subjects. (2008) [23]

\subsection{Study Population}

Healthcare professionals (Medical Consultants, Residents, Medical officers, House officers and Paramedics) practicing in the six tertiary hospitals within South east Nigeria.

\subsection{Operational Definition}

Healthcare professionals are group of people that works in synergy primarily to improve health. [24].

\subsection{Questionnaire Design}

The questionnaire was culled from the guidelines of the Center for Health Protection and the Center for Disease Control and is made up of sections.

1. The basic demographic characteristics and

2. Knowledge and Practice regarding the use of a face mask to limit COVID-19 exposure. [25]. 
The respondent were duly informed on the nature and purpose of the study and informed consent obtained. For ease of analysis each correct answer in the knowledge category and good practice was scored 1 and each incorrect response scored 0 .

\subsection{Data Management and Analysis}

Analysis were conducted using SPSS Software version 21 and two sided p-value of 0.05 was used for all statistical procedures. Descriptive statistics such as Percentages, Mean and Standard deviation were used. T-test and ANOVA were used to assess the relationship between level of knowledge and practice with the standard variables. Pearson correlation coefficient was used to assess the relationship between Knowledge and Practice of the use of medical Masks among Health Care Professionals In South East Nigerian University Teaching Hospitals.

\section{Result}

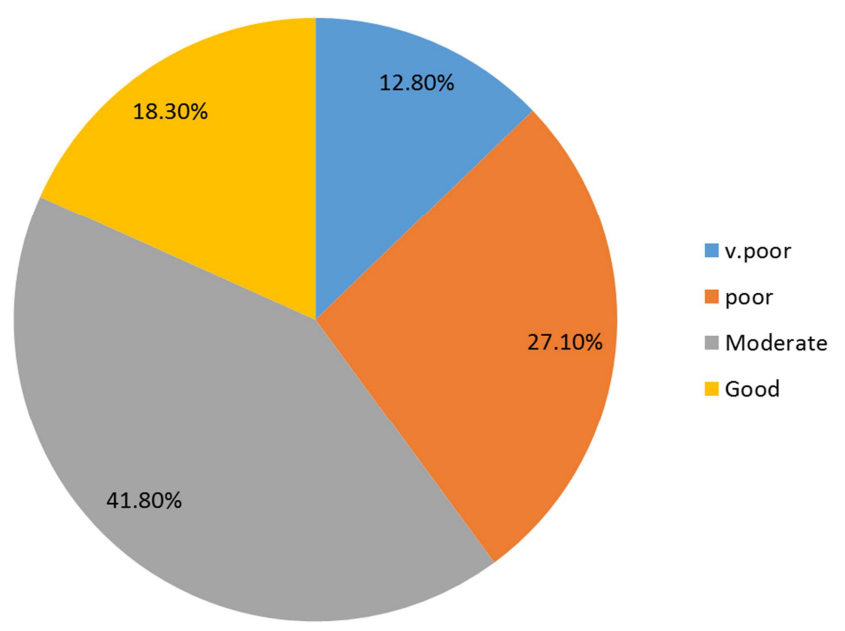

Figure 1. Percentage Distribution of Healthcare professionals that practice correct steps in donning and doffing of medical mask.

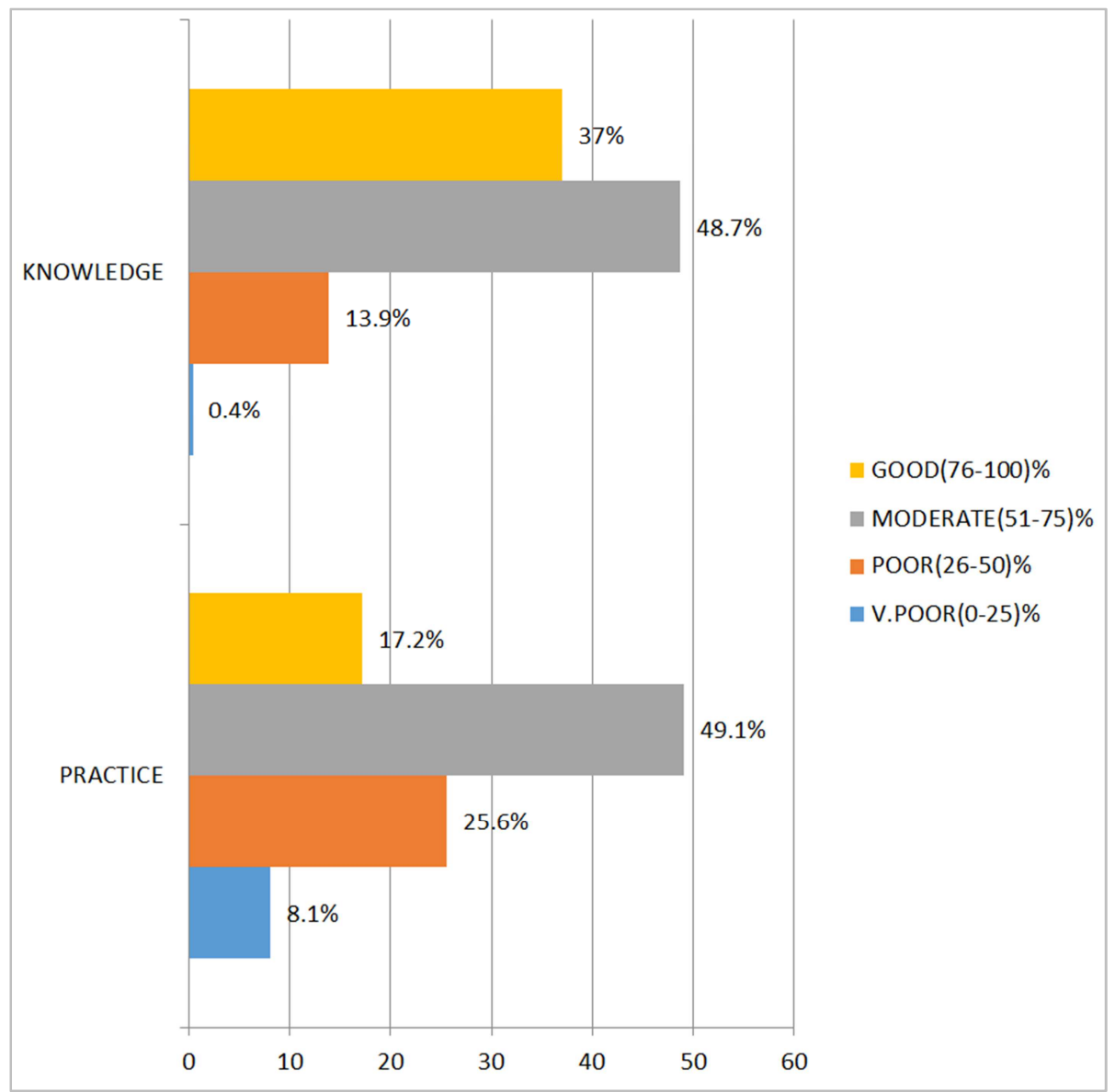

Figure 2. Frequency distribution of knowledge and practice of Healthcare professionals regarding the use of medical mask ( $n=273)$.

Table 1. Relationship between the studied variables (demographic and non demographic) with knowledge and practice of health care workers regarding the use of medical mask $(n=273)$.

\begin{tabular}{lllll}
\hline Parameter & & Knowledge & P-value & Practice \\
\hline & $<30$ years & $6.87 \pm 1.58$ & 0.459 & $12.44 \pm 4.53$ \\
Age (years) ${ }^{* *}$ & 30-40 years & $7.00 \pm 1.42$ & & $13.08 \pm 4.94$ \\
& 41-50 years & $7.00 \pm 1.29$ & $13.24 \pm 4.84$ & 0.745 \\
& 51-60 years & $6.65 \pm 1.34$ & $13.75 \pm 4.04$ & $11.33 \pm 5.69$ \\
\hline
\end{tabular}




\begin{tabular}{llllll}
\hline Parameter & & Knowledge & P-value & Practice & P-value \\
\hline \multirow{2}{*}{ Sex* } & Male & $7.13 \pm 1.28$ & 0.059 & $12.74 \pm 4.84$ & 0.505 \\
& Female & $6.79 \pm 1.52$ & & $13.13 \pm 4.69$ & \\
Education* & Graduate & $6.87 \pm 1.45$ & 0.281 & $13.00 \pm 4.61$ & 0.900 \\
& Post graduate & $7.08 \pm 1.38$ & $0.001^{\wedge}$ & $12.92 \pm 5.15$ & $11.59 \pm 4.42$ \\
& House officers & $6.66 \pm 1.22$ & & $13.08 \pm 5.88$ & \\
& Medical officers & $7.46 \pm 1.61$ & & $13.20 \pm 4.87$ & 0.205 \\
& Resident & $7.65 \pm 1.15$ & $14.86 \pm 2.96$ & \\
& Consultant & $6.57 \pm 1.40$ & & $13.10 \pm 4.79$ & \\
& Paramedics & $6.76 \pm 1.49$ & & & \\
\end{tabular}

*T-test

**ANOVA test.

$\wedge$ Significant relationship.

Table 2. Pearson Correlations between knowledge and practice of the use of medical mask amongst health workers.

\begin{tabular}{llll}
\hline & & Percentage total practice & Percentage total knowledge \\
\hline & Pearson Correlation & 1 & $.147^{*}$ \\
Percentage total practice & P-value & & .015 \\
& $\mathrm{~N}$ & 273 & 273 \\
& Pearson Correlation & $.147^{*}$ & 1 \\
& P-value & .015 & 273 \\
\hline
\end{tabular}

*. Correlation is significant at the 0.05 level (2-tailed).

Table 3. Frequency of participants response to questions related to knowledge and practice of the use of medical mask among health care professionals in tertiary hospitals across southeast Nigeria during covid 19.

\begin{tabular}{|c|c|c|}
\hline \multicolumn{3}{|l|}{ While wearing a N95 or N99 what steps out of following do you follow } \\
\hline Making sure the mask is fit tested for you and you have correct size for you & & $52(18.3)$ \\
\hline Checking its integrity and the elastic bands & & $144(52.7)$ \\
\hline Clean your hands with soap and water or hand sanitizer & & $174(63.7)$ \\
\hline Hold mask over your nose and mouth with the nose clip facing top with the dominant hand & & $130(47.6)$ \\
\hline Holding the top strap and placing it over the crown of your head & & $12(44.3)$ \\
\hline holding the bottom strap and placing it over the base of your neck & & $114(41.8)$ \\
\hline Pinch the nose strip with both hands to mold the shape of your nose. & & $124(45.4)$ \\
\hline Doing the air test (blowing air into your mask and checking if air escapes through the sides) & & $42(15.4)$ \\
\hline Making sure person using N95 or N99 does not have any facial hair & & $35(12.8)$ \\
\hline \multicolumn{3}{|l|}{ While wearing a surgical mask tick the steps you follow } \\
\hline Clean your hands with soap and water, or hand sanitizer & & $206(75.5)$ \\
\hline Hold mask in a way that stiff bendable strip is on top & & $207(75.8)$ \\
\hline Secure mask over your nose and mouth by its band or loops & & $216(79.1)$ \\
\hline Pinch the nose strip to mold to the shape of your nose. & & $207(75.8)$ \\
\hline Pull the bottom of the surgical mask over your mouth and chin & & $197(72.2)$ \\
\hline There should be no gap in between the skin and mask to allow unfiltered air to pass through & & $136(49.8)$ \\
\hline \multicolumn{3}{|l|}{ When removing a mask tick the steps you follow } \\
\hline Clean your hands with soap and water, or hand sanitizer before touching the mask & & $145(53.1)$ \\
\hline Avoid touching front of the mask & & $209(76.6)$ \\
\hline Remove mask by holding the loops/bands & & $237(86.6)$ \\
\hline Dispose of the mask in the trash (not keeping it below your chin or in your pocket when not in use & & $173(63.4)$ \\
\hline Clean your hands with soap and water, or hand sanitizer again before touching anything else & & $180(65.9)$ \\
\hline \multirow{3}{*}{ Before this pandemic, did you wear a medical mask on a regular basis } & Yes & $53(19.4)$ \\
\hline & No & $219(80.2)$ \\
\hline & Yes & $33(12.1)$ \\
\hline \multirow[t]{3}{*}{ Have you received medical evaluation before using the N95 or N99 for the first time } & No & $200(73.3)$ \\
\hline & Idon’t know & $39(14.3)$ \\
\hline & Yes & $25(9.2)$ \\
\hline \multirow[t]{2}{*}{ Do you think surgical mask and N95 mask should be shared or reused } & No & $240(87.9)$ \\
\hline & Idon’t know & $8(2.9)$ \\
\hline \multirow{3}{*}{ Is $\mathrm{N} 95$ or $\mathrm{N} 99$ or $\mathrm{N} 100$ meant for public use } & Yes & $82(30.0)$ \\
\hline & No & $163(59.7)$ \\
\hline & I don't know & $28(10.3)$ \\
\hline
\end{tabular}




\begin{tabular}{|c|c|c|}
\hline While wearing a N95 or N99 what steps out of following do you follow & & \\
\hline \multirow{3}{*}{$\begin{array}{l}\text { Do you think a properly fitted N95 or N99 respirator does not completely eliminate the risk of illness, so it } \\
\text { should be combined with regular hand washing and personal hygiene }\end{array}$} & Yes & $236(86.4)$ \\
\hline & No & $22(8.1)$ \\
\hline & I don't know & $15(5.5)$ \\
\hline \multirow{3}{*}{ Do you think N95 mask offer more protection than surgical mask } & Yes & $226(82.8)$ \\
\hline & No & $39(14.3)$ \\
\hline & I don't know & $8(2.9)$ \\
\hline \multirow[t]{2}{*}{ Do you think surgical mask may help in reducing exposure of your saliva and respiratory secretions to others } & No & $20(7.3)$ \\
\hline & I don't know & $2(0.7)$ \\
\hline
\end{tabular}

\section{Discussion}

The use of medical mask as a protective barrier has gained wide acceptance in reducing the risk involve in the dynamics of transmission of pathogens to patients, health care workers and the environment. [26]. This study aims to ascertain the inherent knowledge gap and practice regarding the use of medical mask by healthcare professionals during Covid-19 pandemic.

In this study it was observed that before this pandemic, $80.2 \%$ of the respondents do not wear medical mask regularly, the use of medical mask was only restricted to some special surgical procedures and as a double barrier in infection prevention control. it was also observed that $73.3 \%$ of the participant thought they knew the procedural steps in the use of medical mask. (Table 3) however Figure 1 shows that only $18.3 \%$ healthcare professionals in our cohort actually had good knowledge on the steps involved in the correct use of medical mask. This findings concurs with the work of [27] Jagdesh kumar et al 2020. $73.3 \%$ of the respondent never received medical evaluation before using the respirator N95 or N99 mask for the first time despite their job rank and experience. (Table 3). This contrast with other studies [28-30] jahangiri et al; 2013; Mortazavi et al; 2011; Nour et al 2015 which attributed that individuals with higher age and job experience received better training and had a better understanding of how to use N95 or N99 mask.

The need and role of health education as an essential factor in the development and sustainability of effective risk control measures cannot be over emphasized. [31]. Figure 2 of this present study reveals that total percentage of participant with good knowledge and practice of the use of medical mask were $37 \%$ and $17.1 \%$ respectively hence there must be safety climate and safety performance among healthcare professionals in other to optimize and reduce the community transmission rate of the novel corona virus 19 during the pandemic.

In this study $82.8 \%$ of the participant also thought that N95 mask offers more protection than surgical mask (Table 3) which did not concur with meta-analysis systematic literature review which reveal that no statistically significant difference exist between an N95 respirator and surgical mask in lowering the risk respiratory viral infection $[32,33]$ however as awareness of healthcare professionals occupational hazards heightens they are likely to be more proactive in the use of preventive measures towards reducing this hazards [34]. An effective knowledge of possible transmission routes of corona virus therefore should translate to practice which will invariably protect the front line healthcare professionals as well as minimize the risk of them getting infected.

In this study, a weak positive correlation was observed between knowledge and practice regarding the use of medical mask among healthcare professionals in southeast Nigeria university teaching hospitals (Table 2). This shows that significant number of the respondent were not able to practice effective ways of donning and doffing medical mask This finding differs from Troungs assessment of knowledge, attitude and practice on use of personal protective equipment in rattan craftsmen at trade village, kienxuong district, thaibinh province, vietnam who reported that the level of knowledge and practice regarding the use of medical mask is low, while all the respondents in their cohort had moderate to high practice. [35].

Considering the relationship among the demographic and non demographic variables in respect to knowledge and practice in our study, descriptive statistics revealed that the level of knowledge and practice were similar irrespective of Age, Sex, Academic qualification. However job rank showed a statistically significant difference. $(p<0.05)$ in the total mean knowledge of the use of medical mask (Table 2). This could be attributed to different level of training and increased years of job experience of the different cadres of health care workers. Unfortunately putting this knowledge to practice did not reveal a statistically significant difference among the different cadres of health care workers.

\section{Conclusion}

The poor knowledge of the use of medical mask among healthcare professionals that has translated to inadequate satisfactory practice were the major contributory indices that has led to continuous community transmission of corona virus infection among healthcare professionals. For a safe healthcare delivery robust continuous medical education on infection prevention control measures especially on the use of personal protective equipment is of utmost important in curbing the spread this virus during the pandemic.

\section{Authors Contribution}

Dr Uche Sebastine Ozioko designed the study protocol and 
analyzed the data and drafted the original manuscript.

Dr Ignatius Ikemefuna Ozor, Dr. Ifeanacho Ezeteonu Abireh, Mrs Onyinye Mary Ozioko. participated in research design, data collection, processing and analysis.

Dr Emmanuel Chino Iyidobi critical review of article before submission for intellectual content.

\section{Conflict of Interest}

No conflict of interest was declared.

\section{Acknowledgements}

We acknowledge Dr Vitus Ezugwu, Dr. Obumneme Oguanya and Dr Onwuegbuchulam for their tremendous assistance all through data collection.

\section{References}

[1] Njidda, Ahmad \& Oyebanji, Oyeronke \& Obasanya, Olusegun \& Ojo, Olubunmi \& Adedeji, Adebayo \& Mba, Nwando \& Oladejo, John \& Ihekweazu, Chikwe. (2018). The Nigeria Centre for Disease Control. BMJ Global Health. 3. e000712. 10.1136/bmjgh-2018-000712.

[2] MacIntyre, CR; Chughtai, AA (9 April 2015). "Facemasks for the prevention of infection in healthcare and community settings". BMJ (Clinical Research Ed.). 350: h694. doi: 10.1136/bmj.h694. PMID 25858901.).

[3] Cascella M, Rajnik M, Cuomo A, Dulebohn SC, Napoli RD (2020): Features, Evaluation and Treatment Coronavirus (COVID-19). In: StatPearls. Treasure Island (FL): StatPearls Publishing.

[4] Adhikari SP, Meng S, Wu Y-J, (2020).: Epidemiology, causes, clinical manifestation and diagnosis, prevention and control of coronavirus disease (COVID-19) during the early outbreak period: a scoping review. Infect Dis Poverty., 9: 29. 10.1186/s40249-020-00646-x.

[5] Sohrabi C, Alsafi Z, O'Neill N, (2020): World Health Organization declares global emergency: A review of the 2019 novel coronavirus (COVID-19). Int J Surg., 76: 71-76. 10.1016/j.ijsu.2020.02.034.

[6] World Health Organization. Statement on the second meeting of the International Health Regulations (2005) Emergency Committee regarding the outbreak of novel coronavirus (2019-nCoV). Available from URL: https://www.who.int/news-room/detail/30-01-2020-statementon-the-second-meeting-of-the-international-healthregulations-(2005)-emergency-committee-regarding-theoutbreak-of-novel-coronavirus-(2019-ncov) (accessed March 2020).

[7] COVID-19 Dashboard by the Center for Systems Science and Engineering (CSSE) at Johns Hopkins University (JHU)". ArcGIS. Johns Hopkins University. Retrieved 13 June 2020.

[8] Ebenso, B.; Otu, A. (2020) Can Nigeria contain the COVID19 outbreak using lessons from recent epidemics? Lancet Glob. Health.

[9] Nigeria Centre for Disease Control. (2020) COVID-19
Outbreak in Nigeria Situation Report; NCDC: Abuja, Nigeria.

[10] "NCDC Covid-19 Page". Nigeria Centre for Disease Control. Retrieved 26 March2020.

[11] Zhou F, Yu T, Du R, (2020): Clinical course and risk factors for mortality of adult inpatients with COVID-19 in Wuhan, China: a retrospective cohort study. Lancet (London, England)., 395: 1054-1062. 10.1016/S0140-6736(20)30566-3).

[12] World Health Organization (2020). Coronavirus Disease (COVID-19) Outbreak: Rights, Roles and Responsibilities of Health Workers, Including Key Consideration for Occupational Safety and Health. Interim guidance 18 March 2020 WHO/2019-nCov/HCW_advice/2020.2.

[13] NCDC Covid-19 update healthwise https://healthwise.punchng.com/812-healthcare-workersinfected-with-covid-19-ncdc/".

[14] Yeo C, Kaushal S, Yeo D. (2020) Enteric involvement of coronaviruses: is faecal-oral transmission of SARS-CoV-2 possible? Lancet Gastroenterol Hepatol. doi: 10.1016/S24681253(20)30048-0.

[15] Centers for Disease Control and Prevention (2020). How COVID-19 spreads. Available from URL: https://www.cdc.gov/coronavirus/2019ncov/about/transmission.html (accessed March 2020).

[16] Afinrud P, Bax CE, Standnystskyi V, Bax A, (2020) Could sarscorv-2 be transmitted via speech droplets? medRxiv 2020).

[17] World Health Organization (2020). Q\&A on coronavirus (COVID-19). Available from URL: https://www.who.int/news-room/q-a-detail/q-a-coronaviruses (accessed March 2020).

[18] European Centre for Disease Prevention and Control. COVID-19. Available from URL: https://www.ecdc.europa.eu/en/novel-coronavirus-china (accessed March 2020).

[19] Centers for Disease Control and Prevention. Isolation Precautions. Available fromURL: https://www.cdc.gov/infectioncontrol/guidelines/isolation/inde x.html (accessed March 2020).

[20] World Health Organization (2020). Infection prevention and control during health care when COVID-19 is suspected. https://www.who.int/publications-detail/infection-preventionand-control-during-health-care-when-novelcoronavirus(ncov)-infection-is-suspected-20200125.

[21] Guidelines on Infection Prevention for Health Care Personnel Caring for Patients with Suspected or Known COVID-19 (2020). Arlington: Infectious Disease Society of America; (https://www.idsociety.org/COVID19guidelines/ip, accessed 4 June 2020).

[22] Siegel JD, Rhinehart E, Jackson M, Chiarello L (2007) guideline for isolation precautions: preventing transmission of infectious agents in health care settings. Am J Infect Control. 2007, 35: 65-164. 10.1016/j.ajic.2007.10.007.

[23] World Medical Association Declaration of Helsinki. (2008). Ethical Principles for Medical Research Involving Human Subjects Internet]. Available from: http://www.net/en/30publication/10polocies/b3/index.html. [Access Date: 13 May 2020]. 
[24] World Health Organisation (2020). Emerging Respiratory Viruses, Including COVID19: Methods for detection, Prevention, Response and Control.

[25] Ho HSW (2012): Use of face masks in a primary care outpatient setting in Hong Kong: knowledge, attitudes, and practices. Public Health. 2012, 126: 1001-1006., Volume 126, Issue 12, Pages 1001-1006, https://doi.org/10.1016/j.puhe.2012.09.010.

[26] Honarbakhsh M, Jahangiri M, Ghaem H (2018): Knowledge, perceptions, practice of Healthcare professionals regarding the use of respiratory protection equipment at Iran hospital. J. Infect Prev., 19: 29-36.

[27] Jagdesh Kumar, Muhammad Soughat Katto, Adeel A Siddiqui, Badaruddin Sahito, Muhammad Jamil, Nusrat Rasheed, and Maratib Ali. (2020): Knowledge, Attitude and Practices of Health Workers Regarding the use of face mask to limit the spread of the new corona virus disease. Cureus 2020 Apr; 12 (4): e7737.

[28] Jahangiri M, Sareban Zadeh K, Bashar OL Saleh Zadeh H. (2013). Risk perception, safety attitude and safety performance in supervisors of construction sites in shiraz. Journal of Ergonomics 1: 10-18.

[29] Mortazavi S, Asilian H, Oostakhan M. (2011). The relationship between safety climate factors and workers behavior working in potentially dangerous situations in height among construction workers. Iranian Journal of Public Health 8: 51-60.
[30] Nour MO, Babilghith AO, Natto HA, AL-Amin FO, Alawneh SM. (2015). Knowledge, attitude and practices of healthcare providers towards MERS-CoV infection at Makkah hospitals, KSA. International Research Journal Of Medicine and Medical Sciences 3: 103-112.

[31] Cohen, A \& Colligan, M. J. (1995). Assessing occupational safety and health training: A literature review. Worker health and Safety, 22.

[32] Long Y, Hu T, Liu L, Chen R, Guo Q, Yang L, (2020). Effectiveness of N95 respirators versus surgical mask against influenza: A systematic review and meta-analysis. J. Evid Based Med.; 13 (2): 93-101.

[33] Jefferson, T., Jones M, Al Ansari, L. A., Bawazeer, G., Beller, E., Clark (2020). Physical interventions to interrupt or reduce the spread of respiratory viruses. Part 1-Face masks, eye protection and person distancing: systematic review and metaanalysis. MedRxiv.

[34] Laughery K. R \& Brelsford J. W (1993). Receiver characteristics in safety communication. Human factor perspective on warning California. The Human factors and Ergonomics Society: 120-124.

[35] Truong CD, Siriwong W, Robson M. G. (2009) Assessment of knowledge, attitude and practice on using of personal protective equipment in rattan craftsmen at trade village, kienxuong district, thaibinh province, vietnam. warasan wichai witthayasat kanphaet.; 23 (Suppl): 1-4. 